\title{
PELAKSANAAN SISTEM SURVEILANS KESEHATAN HAJI DI DINAS KESEHATANKOTA SURABAYA
}

\author{
Implementation of Haji Health Surveillance System \\ in The Health City of Surabaya
}

\author{
Krisnita Dwi Jayanti \\ Fakultas Ilmu Kesehatan, Institut Ilmu Kesehatan Bhakti Wiyata Kediri \\ Email : krisnita.jayanti@iik.ac.id, 082141614049
}

\begin{abstract}
Indonesian's Hajj pilgrims were mostly high-risk pilgrims. Information system and epidemiological surveillance aimed to obtain information that can be used as feedback for planning, controlling, monitoring and evaluation of health pilgrimage.This study aimed to describe the implementation of hajj health surveillance in Surabaya Health Office.This research used descriptive method with cross sectional design. Respondents were the officers of hajj health surveilance program in Surabaya Health office. Data sources were primary and secondary data.The result showed that the data collection component from of data at risk hajj as much as 1428 (67\%), the highest number of [ilgrims aged 50-59 years 763 (36\%), the pilgrims at most women 1138 (54\%), pregnancy tests with negative results of 640 (56\%), and the congregation in the observation 1375 (65\%). The program used to process the data is hajj integrated health system (SISKOHATKES) system is online. Epidemiological information of all pilgrims who departed must be recorded 100\%, the pilgrims were examined 3 months before leaving still reaches 73\% that should be 80\%. The output of Hajj Surveilance was disseminated to Public Health Centers at the end of hajj season through monthly meetings.
\end{abstract}

Keywords : Surveillance, Health of hajj, implementation, Surabaya City

\begin{abstract}
Abstrak
Jamaah haji di Indonesia sebagian besar merupakan jamaah haji yang memiliki risiko tinggi.Penyelenggaran Sistem Informasi dan Surveilans Epidemiologi bertujuan untuk mendapatkan informasi yang dapat dimanfaatkan sebagai bahan dalam perencanaan, pengendalian, monitoring dan evaluasi penyelengaraan haji, terutama bidang kesehatan. Penelitian ini bertujuan untuk mendiskripsikan pelaksanaan sistem surveilans kesehatan haji di Dinas Kesehatan Kota Surabaya. Penelitian ini menggunakan metode deskriptif dengan rancangan cross sectional. Responden adalah pelaksana program surveilans kesehatan haji di Dinas Kesehatan Kota Surabaya. Sumber data adalah data primer dan data sekunder. Hasil penelitian menunjukkan bahwa komponen pengumpulan data berupa data jamaah berisiko sebanyak 1428 (67\%), umur terbanyak jamaah haji berusia 50-59 tahun 763 (36\%), jamaah haji paling banyak berjenis kelamin wanita 1138 (54\%), pemeriksaan kehamilan dengan hasil negatif sebanyak 640 (56\%), dan kategori jamaah dalam observasi sebanyak 1375 (65\%). Program yang digunakan untuk mengolah data adalah sistem Komputer Terpadu Kesehatan Haji (SISKOHATKES) yang dilakukan secara Krisnita Dwi Jayanti adalah Fakultas Ilmu Kesehatan, Institut Ilmu Kesehatan Bhakti Wiyata Kediri
\end{abstract}


online.Analisis data dilakukan dengan SISKOHATKES secara online. Informasi epidemiologi berupa informasi cakupan seluruh jamaah yang berangkat harus terekam $100 \%$, jamaah yang diperiksa 3 bulan sebelumberangkat masih mencapai $73 \%$ seharusnya 80\%. Output dari surveilans kesehatan haji berupa diseminasi informasi berupa laporan dan umpan balik ke puskesmas pada akhir musim haji melalui rapat bulanan.

Kata kunci : Surveilans, Kesehatan Haji, Pelaksanaan, Kota Surabaya

\section{PENDAHULUAN}

Ibadah haji dilaksanakan kaum muslim dan muslimah dari seluruh penjuru dunia yang terdiri dari berbagai suku dan bangsa.Jamaah haji memiliki latar belakang penyakit endemis dan epidemi masingmasing,sehinggamemiliki risiko terjadi penularan penyakit antar jamaah haji terutama penyakit menular. Penyakit yang berisiko menular antara lain meningitis, TBC, hepatitis, diare, kholera, influenza, dan lain lain.1Penyakit baru yang perlu di Waspadai menular pada saat melakukan ibadah haji yaitu MERSCoV dan virus ebola. ${ }^{2}$

Indonesia merupakan negara dengan jumlah muslim terbanyak di dunia, sehingga Indonesia merupakan negara terbanyak yang mengirimkan jamaah haji ke Arab Saudi. Indonesia berisiko tinggi tertular penyakit dari penyakit menular yang sedang endemis di Arab Saudi atau negara lain yang ikut dalam ibadah haji. Masa tunggu jamaah berangkat tahun 2014 minimal 5 tahun, sedangkan jamaah haji yang melakukan pendaftaran saat ini lebih panjang lagi waktu tunggu keberangkatan haji yaitu lebih dari 17 tahun. Lama tunggu yang relatif lama menyebabkan banyaknya jamaah haji yang telah lanjut usia, banyakjamaah haji lanjut usia merupakan faktor risiko kesehatan haji, seperti lemahnya kekuatan fisik, mudah terserang penyakit, sulit beradaptasi dengan lingkungan, maupun banyaknya penyakit degeneratif yang diderita oleh para lanjut usia. ${ }^{3}$

Jamaah haji di Indonesia sebagian besar merupakan jamaah haji yang memiliki risiko tinggi. Jamaah haji risiko tinggi kesehatan adalah jamaah haji dengan kondisi kesehatan yang secara epidemiologi berisiko sakit dan atau mati selama perjalanan ibadah haji, meliputi jamaah haji lanjut usia, jamaah haji penderita penyakit menular tertentu yang tidak boleh terbawa keluar dari Indonesia, jamaah haji wanita hamil, dan jamaah haji dengan ketidak mampuan tertentu terkait penyakit kronis dan atau penyakit tertentu lainnya. ${ }^{3}$

Penyelenggaraan ibadah haji, sebagaimana diamanatkan dalam Undang-Undang nomor 13 Tahun 2008, bertujuan untuk memberikan pembinaan, pelayanan, dan perlindungan yang sebaik-baiknya bagi jamaah haji pada bidang kesehatan agar jamaah haji dapat menunaikan ibadah dengan baik sesuai ketentuan ajaran Islam. Tujuan tersebut dicapai melalui upaya-upaya peningkatan kondisi kesehatan sebelum keberangkatan, menjaga kondisi sehat selama menunaikan ibadah sampai tiba kembali ke Indonesia, serta mencegah transmisi penyakit menular yang mungkin terbawa keluar/mas Krisnita Dwi Jayanti :Pelaksa jamaah haji. ${ }^{3}$

Penyelenggaraan pelayanan dan pembinaan kesehatan haji diperlukan mekanisme pencatatan dan pelaporan 
informasi kesehatan jamaah haji secara cepat, tepat dan berkesinambungan yang terkoordinasi dengan Sistem Komputerisasi Haji Terpadu bidang Kesehatan (SISKOHATKES) berbasis web. Sistem komputerisasi Haji Terpadu Kesehatan merupakan kegiatan pengamatan/surveilans yang dilakukan secara sistematis dan berkesinambungan dalam suatu siklus musim haji dengan menggunakan sistem komputerisasi. ${ }^{1}$

Data pemeriksaan awal status kesehatan jamaah haji sebagian masih mempunyai risiko tinggi. Proporsi jamaah haji risiko tinggi berkisar 30$45 \%$, sebagian besar karena usia lanjut. Hipertensi dan diabetes Mellitus merupakan penyakit risiko tinggi terbanyak (25-37\%), sementara penyakit saluran pernafasan dan saluran pencernaan semakin meningkat jumlahnya dari tahun ke tahun. Jamaah haji memiliki risiko pada kelompok usia 60 tahun ke atas berjumlah sekitar 70\% dari semua jamaah haji. Hal ini menunjukkan bahwa pembinaan kesehatan jamaah haji pada kelompok usia tersebut belum optimal. Masalah lain yang timbul adalah hampir separuh kematian tersebut terjadi diluar sarana layanan kesehatan, kematian terbanyak terjadi dipondokan, sementara akses jamaah terhadap pelayanan kesehatan masih cukup rendah (hanya < 15\% jamaah akses terhadap pelayanan kesehatan dan 1-1,5\% dari total jamaah dirawat inap di sarana layanan kesehatan baik BPHI maupun RS Arab Saudi). ${ }^{4}$

Kesehatan adalah modal perjalanan ibadah haji, tanpa kondisi kesehatan yang memadai, kegiatan ibadah haji tidak dapat berjalan maksimal. Oleh karena itu setiap 106 Jurnal IKESMA Volume 13 Nomor 2 September 2017 memiliki status kesehatan optimal dan mempertahankannya. Untuk itu, upaya utama yang perlu ditempuh adalah pemeriksaan kesehatan. Pemeriksaan kesehatan merupakan upaya identifikasi status kesehatan sebagai landasan karakterisasi, prediksi dan penentuan cara eliminasi faktor risiko kesehatan. ${ }^{3}$

Penyelenggaraan kesehatan haji terdiri dari rangkaian kegiatan pelayanan kesehatan haji meliputi pemeriksaan kesehatan, bimbingan dan penyuluhan kesehatan haji, pelayanan kesehatan, imunisasi, surveilans, SKD dan respon KLB, penanggulangan KLB dan musibah massal, kesehatan lingkungan dan manajemen kesehatan haji. Penyelenggaran Sistem Informasi dan Surveilans Epidemiologi bertujuan untuk mendapatkan informasi yang dapat dimanfaatkan sebagai bahan dalam perencanaan, pengendalian, monitoring dan evaluasi penyelengaraan haji, terutama bidang kesehatan, serta menunjang pelaksanaan sistem kewaspadaan dini dan respon kejadian luar biasa penyakit dan keracunan. ${ }^{5}$

Berdasarkan

latar belakangtersebutmaka, ingin mengetahui gambaran pelaksanaan surveilans kesehatan Haji di Dinas Kesehatan Kota Surabaya. Analisis dilakukan dengan melihat gambaran mengenai sistem surveilans kesehatan haji di Dinas Kesehatan Kota Surabaya serta bisa mengetahui masalah dalam pelaksanaan surveilans kesehatan haji. Tujuan penelitian ini adalah mendiskripsikan pelaksanaan sistem surveilans kesehatan haji di Kota Surabaya tahun 2014.

\section{METODE PENELITIAN}


Penelitian ini merupakan penelitian deskriptif dengan pendekatan observasional. Desain penelitian yang digunakan adalah cross sectional yaitu melihat pelaksanaan surveilans kesehatan haji tahun 2014. Responden penelitian adalah pelaksana progam kesehatan haji di Dinas Kesehatan Kota Surabaya. Pengumpulan data dilakukan dengan wawancara dan studi dokumentasi. Analisis data dilakukan secara deskriptif dengan cara membandingkan hasil penelitian yang diperoleh di lapangan dengan teori dan atau pedoman program. Hasil analisis diuraikan dalam bentuk narasi untuk mendeskripsikan variabel penelitian, kemudian digambarkan dalam bentuk tabel, grafik dan gambar.

\section{HASIL PENELITIAN DAN PEMBAHASAN}

\section{Identifikasi Masalah Kesehatan Haji di Kota Surabaya}

Ibadah haji adalah rukun Islam

kelima yang merupakan kewajiban seumur hidup bagi setiap orang Islam yang mampu menunaikannya. Jamaah haji adalah warga Negara Indonesia yang beragama Islam dan telah mendaftarkan diri untuk menunaikan ibadah haji sesuai dengan persyaratan yang ditetapkan. Penyelenggaraan ibadah haji adalah rangkaian kegiatan pengelolaan pelaksanaan Ibadah haji yang meliputi pembinaan, pelayanan dan perlindungan jamaah haji. ${ }^{5}$

Kesehatan merupakan modal utama untuk kelancaran pelaksanaan ibadah haji. Kesehatan sangat dipengaruhi oleh lingkungan sekitar, jamaah haji dengan waktu tunggu keberangkatan yang lama menyebabkan banyak permasalahan kesehatan yang dapat terjadi pada jamaah haji. Jamaah haji yang memiliki risiko (jamaah dengan potensi masalah kesehatan) yaitu jamaah yang berusia lanjut (60 tahun atau lebih), hamil dan menderita sakit kronis berat. ${ }^{3}$ Berikut hasil laporan pelaksanaan surveilans kesehatan haji tahun 2014 :

Jamaah Haji Kota Surabaya Berdasarkan Risiko dapat dilihat pada tabel 1 berikut :

Tabel 1. Distribusi frekuensi jamaah haji berdasarkan Risiko Jamaah Haji Di Kota Surabaya

\begin{tabular}{clccc}
\hline No & \multicolumn{1}{c}{ Risiko } & F & \% \\
\hline 1 & Sehat & 697 & 33 \\
2 & Memiliki Risiko Tinggi & 1428 & 67 \\
& & & \\
\hline & & 2125 & 100 \\
\hline
\end{tabular}

(Sumber : Data Primer Dinas Kesehatan Kota Surabaya 2014)

Dari tabel 1 tersebut dapat diketahui Datajamaah haji memiliki risiko kesehatan sebanyak $1.428(67 \%)$ jamaah, dan jamaah yang sehat sebanyak 697 (33\%). Jamaah memiliki risiko seperti jamaah haji yang berusia lanjut $\geq$ 60 tahun, jamaah haji penderita penyakit menular tertentu, jamaah haji wanita hamil dan jamaah haji dengan ketidakmampuan tertentu terkait penyakit kronis seperti diabetes mellitus dengan komplikasi dan gangren serta penderita penyakit kanker, dan atau penyakit tertentu lainnya. ${ }^{3}$ Penyakit menular yang menjadi perhatian WHO yaitu tuberkulosis paru dengan BTA positip, kusta tipe multi basiler, SARS(Severe Acute Respiratory Syndrome), Avian influenza (AI), influenza A baru (H1N1)dan penyakit 
menular lain yang ditentukan kemudian. ${ }^{3}$ Kegiatan ibadah haji merupakan kegiatan dengan kumpulan banyak individu, sehingga berpotensi untuk terjadi transmisi epidemi penyakit rawan di tempat haji, sehingga perlu diterapkan kegiatan sistem surveilans kesehatan haji. ${ }^{8}$

\section{Jamaah Haji Kota Surabaya Berdasarkan Golongan Umur}

Tabel 2. Distribusi Frekuensi Jamaah Haji Di Kota Surabaya Berdasarkan Golongan Umur

\begin{tabular}{clcc}
\hline No & Umur & $\mathbf{F}$ & $\mathbf{\%}$ \\
\hline 1 & $<19$ Tahun & 3 & 0 \\
2 & 20-29 Tahun & 47 & 2 \\
3 & 30-39 Tahun & 214 & 10 \\
4 & 40-49 Tahun & 534 & 25 \\
5 & 50-59 Tahun & 763 & 36 \\
6 & $\geq 60$ Tahun & 564 & 27 \\
\hline & Jumlah & 2125 & 100
\end{tabular}

(Sumber : Data Primer Dinas Kesehatan Kota Su 108 Jurnal IKESMA Volume 13 Nomor 2 September 2017

Berdasarkan tabel 2Golongan umur jamaah haji terbanyak yang melaksanakan ibadah haji adalah pada golongan umur50-59 tahun sebanyak 763 (36\%)jamaah.Golongan umur Jamaah haji yang berusia 60 tahun yang perlu menjadi perhatian karena merupakan kelompok umur yang memiliki risiko masalah kesehatan berjumlah 564 (27\%)jamaah.Berdasarkan penelitian sebelumnya menunjukkan bahwa risiko terjadinya kematian pada jamaah haji tertinggi banyak terjadi pada umur $\geq 60$ tahun dan angka kematian tersebut meningkat seiring pertambahan umur jamaah. ${ }^{9}$ Ibadah haji merupakan kegiatan ibadah yang membutuhkan kekuatan fisik dan kesehatan yang prima. Golongan umur yang banyak pada usia lanjut menyebabkan banyaknya risiko permasalahan kesehatan karena kemampuan tubuh dan kekuatan fisik dari jamaah haji usia lanjut yang menurun karena usia lansia tersebut.
Golongan umur jamaah haji digunakan untuk mengetahui kemungkinan masalah kesehatan yang dapat terjadi dilihat dari umur jamaah haji tersebut. Data jamaah haji di Kota Surabaya berdasarkan golongan umur menggunakan data yang dikeluarkan oleh Dinas Kesehatan Kota Surabaya Tahun 2014 yaitu pada tabel 1 berikut : 
berangkat.

\section{Jenis Kelamin Jamaah Haji}

Jenis kelamin merupakan hal yang juga menjadi perhatian terkait dengan permasalahan kesehatan yang bisa menjadi faktor risiko bagi jenis kelamin tertentu. Datajamaah haji berdasarkan jenis kelamin di Kota Surabayadapat dilihat pada tabel 3 berikut :

Tabel 3. Distribusi Frekuensi Jenis Kelamin Jamaah Haji Di Kota Surabaya

\begin{tabular}{clcc}
\hline No & Jenis Kelamin & F & \% \\
\hline 1 & Laki-laki & 987 & 46 \\
2 & Wanita & 1138 & 54 \\
\hline \multicolumn{2}{r}{ Jumlah } & 2125 & 100 \\
\hline
\end{tabular}

(Sumber : Data Primer Dinas Kesehatan Kota Surabaya 2014)

Dari tabel 3 tersebut dapat diketahui jumlah jamaah haji kota Surabaya pada tahun 2014 terbanyak adalah jamaah haji perempuan dengan jumlah 1.138(56\%)jamaah. Berdasarkan penelitian sebelumnya menunjukkan bahwa risiko terjadi kematian lebih dominan terjadi pada jemaah haji lakilaki. ${ }^{9}$ Jenis kelamin jamaah haji digunakan untuk mengetahui risiko yang mungkin bisa terjadi selama perjalanan ibadah haji. Jamaah haji banyak yang berjenis kelamin perempuan sehingga harus diperhatikan tentang status kehamilan jamaah. Kehamilan yang terjadi pada saat melakukan ibadah haji apabila tidak di kelola dengan baik akan berisiko bagi jamaah dan juga anak yang dikandung dari penyakit meningitis yang endemik di Arab Saudi.

\section{Pemeriksaan Kehamilan pada Jamaah Haji \\ Data pemeriksaan kehamilan jamaahhaji di Kota Surabayadapat dilihat pada tabel 4 berikut :}

Tabel 4. Distribusi Frekuensi Hasil Pemeriksaan Kehamilan Jamaah Haji Di Kota Surabaya

\begin{tabular}{clcc}
\hline No & Pemeriksaan Kehamilan & F & $\mathbf{\%}$ \\
\hline 1 & Positif Hamil & 0 & 0 \\
2 & Negatif Hamil & 640 & 56 \\
3 & Tidak diperiksa & 498 & 44 \\
\hline & Jumlah & 1138 & 100
\end{tabular}

(Sumber : Data Primer Dinas Kesehatan Kota Surabaya 2014)

Dari tabel 4 tersebut dapat diketahui bahwa total jamaahberjenis kelamin perempuan berjumlah 1138 dan jumlah jamaah haji yang tidak diperiksa kehamilan sebanyak 498 (44\%)jamaah. Tidak ada jamaah haji wanita yang positif hamil.Jamaah haji yang tidak diperiksa kehamilan tersebut karena 498 jamaahberjenis kelamin perempuan yang sudah mengalami menopouse.
Pemeriksaan kehamilan penting untuk mengetahui status kehamilan seseorang. Kehamilan menjadi berisiko untuk tertular penyakit meninggitis, sehingga pemeriksaan kehamilan perlu dilakukan. Apabila terdapat Calon jamaah haji wanita hamil yang diizinkan untuk menunaikan ibadah haji harus memenuhi syarat yaitu telah mendapatkan suntikan vaksinasi meningitis paling lama 2 tahun 
sebelum keberangkatan haji dengan bukti International Certificate of Vaccination (ICV) yang sah. Pada saat berangkat dari embarkasi usia kehamilan mencapai sekurang-kurangnya 14 (empat belas) minggu dan sebanyakbanyaknya 26(dua puluh enam) minggu. Tidak tergolong dalam kehamilan risiko tinggi, baik untuk ibu serta janinnya, yang dinyatakan dengan surat keterangan dari dokter spesialis kebidanan dan penyakit kandungan yang memiliki surat izin praktik.

Kategori Hasil Pemeriksaan
Kesehatan Jamaah Haji
Pemeriksaan kesehatan jamaah haji
dilakukan di Puskesmas melalui
pemeriksaan pertama dan pemeriksaan
kedua. Data hasil pemeriksaan kesehatan
jamaah haji di Kota Surabaya
menggunakan data yang dikeluarkan
oleh Dinas Kesehatan Kota Surabaya
tahun 2014 dapat diketahui
pada tabel 5 berikut :

Tabel 5. Distribusi Frekuensi Kategori Hasil Pemeriksaan Kesehatan Jamaah Haji Di Kota Surabaya

\begin{tabular}{|c|c|c|c|}
\hline No & Kategori & $\mathbf{F}$ & $\%$ \\
\hline 1 & Mandiri & 697 & 33 \\
\hline 2 & Observasi & 1375 & 65 \\
\hline 3 & Pengawasan & 53 & 2 \\
\hline 4 & Tunda & 0 & 0 \\
\hline & Jumlah & 2125 & 100 \\
\hline
\end{tabular}

(Sumber : Data Primer Dinas Kesehatan Kota Surabaya 2014)

Dari tabel 5 tersebut Dapat diketahui bahwa dari hasil pemeriksaan pertama dan pemeriksaan keduastatus jamaah haji terbanyak adalah jamaah dengan status observasi sebesar 1.375(65\%)jamaah.Jamaah haji observasi adalah jamaah haji yang memiliki kemampuan mengikuti perjalanan ibadah haji dengan bantuan alat dan atau obat. jamaah haji yang berstatus mandiri sebanyak 697 (33\%). Jamaah haji mandiri adalahjamaah haji yang memiliki kemampuan mengikuti perjalanan ibadah haji tanpa tergantung kepada bantuan alat atau obat dan orang lain. Jamaah haji pengawasan adalah jamaah haji yang memiliki kemampuan mengikuti perjalanan ibadah haji dengan bantuan alat dan atau obat dan orang lain. ${ }^{3}$ Jamaah dengan status pengawasan sebanyak 53 (2\%), banyaknya jumlah jamaah observasi menyebabkan tenaga kesehatan menjadi lebih banyak melakukan upaya memberikan pelayanan yang optimal agar jamaah haji observasi bisa melaksanakan ibadah haji.

\section{PenyakitJamaah Haji Di Kota Surabaya}

Dari hasil pemeriksaan pertama dan pemeriksaan kedua yang dilakukan oleh petugas puskesmas diperoleh data pada tabel 6 berikut

\section{Jurnal IKESMA Volume 13 Nomor 2 September 2017}

Tabel 6. Distribusi Frekuensi 5 Penyakit Jamaah Haji Di Kota Surabaya 


\begin{tabular}{|c|c|c|c|c|}
\hline No & Kode ICD X & Hasil Pemeriksaan Kedua & $\mathrm{F}$ & $\%$ \\
\hline 1 & $\mathrm{Z00}$ & $\begin{array}{l}\text { General examination and } \\
\text { investigastion of persons } \\
\text { without complaintor reported } \\
\text { diagnosis }\end{array}$ & 567 & 27 \\
\hline 2 & $\mathrm{I} 10$ & $\begin{array}{l}\text { Essential } \\
\text { hypertension }\end{array}$ & 547 & 26 \\
\hline 3 & R54 & Senility & 418 & 20 \\
\hline 4 & E11 & $\begin{array}{l}\text { Non-insulin-dependent } \\
\text { diabetes mellitus }\end{array}$ & 245 & 11 \\
\hline 5 & E78 & $\begin{array}{l}\text { Disorders of lipoprotein } \\
\text { metabolism and other } \\
\text { lipidaemias }\end{array}$ & 226 & 10 \\
\hline 6 & $\mathrm{E} 88,9$ & $\begin{array}{l}\text { Metabolic } \\
\text { unspecified }\end{array}$ & 122 & 6 \\
\hline
\end{tabular}

(Sumber : Data Primer Dinas Kesehatan Kota Surabaya 2014)

Dari tabel 6 tersebut dapat diketahui bahwa 5 penyakit terbanyak yang diderita jamaah haji di Kota Surabayadiketahui bahwa penyakit terbanyak adalah penyakit hipertensi dengan jumlah penderita 547 (26\%)jamaah.Penyakit kedua terbanyak adalah dementia (senility) sebanyak 418 (20\%)jamaah.Penyakit ketiga adalah diabetes mellitus non insulin sebanyak 245 (11\%)jamaah.Jamaah yang sehat hanya berjumlah $567(27 \%)$ dari total jamaah pada tahun 2014 adalah 2125 jamaah.Berdasarkan penelitian sebelumnya yang dilakukan selama 5 tahun berturut-turut penyakit yang paling banyak diderita oleh jamaah haji Iran adalah hipertensi. Penyakit hipertensi sangat umum terjadi pada populasi kebanyakan dengan prevalensi 10 sampai 20 persen.11Penyakit sirkulasi terutama penyakit pembuluh darah jantung seperti hipertensi umumnya terjadi karena jantung gagal memompa darah ke seluruh tubuh, kurangnya oksigen yang dibawa oleh darah ke jantung atau tertutupnya pembuluh darah karena penyempitan. ${ }^{2}$ Penyakit yang paling banyak tersebut, dikarenakan banyaknya jumlah jamaah haji di Kota Surabaya yang berusia lanjutyaitu 50-59 tahun dan $\geq 60$ tahun.

\section{Gambaran Pelaksanaan Sistem Surveilans Kesehatan Haji Di Dinas Kesehatan Kota Surabaya}

Surveilans epidemiologi adalah kegiatan analisis secara sistematis dan terus menerus terhadap penyakit dan masalah - masalah kesehatan serta kondisi yang memperbesar risiko terjadinya peningkatan dan penularan penyakit serta masalah - masalah kesehatan tersebut agar dapat melakukan tindakan penanggulangan secara efektif dan efisien melalui proses pengumpulan data, pengolahan dan penyebaran informasi epidemiologi kepada penyelenggara program kesehatan. ${ }^{7}$

Penyelenggaraan surveilans kesehatan dilakukan melalui pengumpulan data, pengolahan data, analisisdata, dan diseminasi sebagai satu kesatuan yang tidak terpisahkan untuk menghasilkan suatu informasi yang objektif, terukur, dpat diperbandingkan anatar waktu, 
antar wilayah serta berdasarkan dimensi waktu, tempat dan orang. ${ }^{8}$

\section{Batasan Sistem Surveilans Kesehatan Haji di Dinas Kesehatan Kota Surabaya}

Sistem surveilans kesehatan hajidi Dinas Kesehatan Kota Surabaya merupakan kegiatan surveilans kesehatan jamaah haji berdasarkan pemeriksaan kesehatan di daerah berupa analisis secara sistematis dan terus-menerus terhadap penyakit atau masalah-masalah kesehatan jamaah haji dan kondisi yang mempengaruhi terjadinya peningkatan dan penularan penyakitpada jamaah haji yang terdapat di wilayah kerja Dinas Kesehatan Kota Surabaya melalui kegiatan pemeriksaan kesehatan awal dan pemeriksaan kesehatan lanjutan yang dilakukan oleh Puskesmas pada jamaah haji.

Tujuan Sistem Surveilans Kesehatan Haji di Dinas Kesehatan Kota Surabaya sebagai berikut :

a. Mengendalikan pelaksanaan pemeriksaan kesehatan pada jamaah haji

b. Mengendalikan pelaksanaan imunisasi pada jamaah haji

c. Mengendalikan pelaksanaan bimbingan dan penyuluhan kesehatan pada jamaah haji

d. Mengendalikan pelaksanaan pelayanan kesehatan pada jamaah haji

e. Melakukan pengamatan penyakit pada jamaah haji

f. Melaksanakan bimbingan tehnis penyelenggaraan kesehatan haji

g. Melaksanakan pelatihan tentang penyelenggaraan kesehatan haji

h. Melakukan SKD-respon KLB

i. Melakukan monitoring dan evaluasi

j. Melakukan pencatatan dan pelaporan k. Melaksanakan kesiapsiagaan dan penanggulangan kejadian musibah massal

Definisi dari sistem surveilans kesehatan haji yang diterapkan oleh Dinas Kesehatan Kota Surabaya sudah sesuai dengan tujuan dan definisi yang ditetapkan oleh Departemen Kesehatan Republik Indonesia yaitu Surveilans epidemiologi kesehatan haji merupakan kegiatan analisis secara sistematis dan terus menerus terhadap penyakit atau masalah - masalah kesehatan jamaah haji dan kondisi yang mempengaruhi terjadinya peningkatan dan penularan penyakit atau masalah-masalah kesehatan haji, agar dapat melakukan tindakan penanggulangan dan penyebaran informasi epidemiologi kepada penyelenggara program kesehatan haji. ${ }^{3}$

\section{Gambaran Sistem Surveilans Kesehatan Haji yang sedang berjalan di Dinas Kesehatan Kota Surabaya}

Pelaksanaan kegiatan surveilans secara keseluruhan dapat berjalan dengan efektif maka perlu adanya manajemen kegiatan mulai dari perencanaan sampai dengan evaluasi melalui pendekatan sistem yaitu input, proses, output. Suatu sistem adalah jaringan kerja dari prosedur-prosedur yang saling berhubungan, berkumpul bersama sama untuk melakukan suatu kegiatan. Sistem merupakan kumpulan elemen elemen yang saling terkait dan bekerja sama untuk memproses masukan (input) yang ditujukan kepada sistem tersebut dan mengolah masukan tersebut sampai menghasilkan keluaran (output) yang diinginkan. Pelaksanaan surveilans kesehatan haji berdasarkan komponen sistem surveilans kesehatan hajiyaitu : 


\section{Gambaran Input (Masukan)}

Input merupakan elemen dari sistem yang bertugas untuk menerima seluruh masukan data, dimana masukan tersebut berupa jenis data, frekuensi pemasukan data dan lain-lain.

\section{a. Sumber daya manusia (Man)}

Tim pemeriksa kesehatan haji terdiri dari tenaga fungsional kesehatan yang ada di Puskesmas, terdiri dari tenaga fungsional kesehatan yang ada di Puskesmas antara lain dokter, perawat, analis laboratorium, surveilans, ahli gizi dan farmasi atau di atur oleh masingmasing Dinas Kesehatan Kota Surabaya. Petugas surveilans kesehatan hajibertugas secara khusus dari melakukan pemeriksaan pertama dan pemeriksaan kedua.Tenaga sudah memenuhi kebutuhan yaitu terdiri dari : 1 (satu) orang koordinator dan penanggungjawab; 62 tenaga entri data di 62 Puskesmas Di wilayah Kerja Dinas Kesehatan Kota Surabaya; 62 dokter pemeriksa; 62 tenaga imunisasi (bidan atau perawat); serta 62 tenaga posbindu.

\section{b. Dana (Money)}

Dana digunakan untuk kegiatan program pelayanan kesehatan haji dalam bentuk penyuluhan kesehatan jamaah haji, pelayanan klinik kesehatan jamaah haji, obat-obatan, dan sebagainya. Dana untuk kegiatan surveilans kesehatan haji dalam bentuk dana operasional, bahan, kartu kewaspadaan kesehatan jamaah haji dan bahan untuk penyuluhan kesehatan haji. Sumber dana surveilans kesehatan haji berasal dari APBD.

\section{c. Sarana dan Bahan (Material)}

Sarana yang digunakan dalam kegiatan surveilans kesehatan haji yaitu 1 set komputer yang dilengkapi dengan printer berwarna serta koneksi data internet yang telah tersedia di 62 puskesmas. Sarana ini telah dianggap cukup untuk melaksanakan kegiatan surveilans kesehatan haji.Program yang digunakan untuk mengolah data adalah sistem Komputer Terpadu Kesehatan Haji (SISKOHATKES) yang dilakukan secara online.

Kendala pada pelaksanaannya SISKOHATKES masih belum berjalan optimal Karena terkendala permasalahan internet yang kurang mendukung sehingga dalam memasukkan data membutuhkan waktu yang lama sehingga menggunakan sistem offline dengan E-BKJH kemudian di upload terkadang masih lama untuk mengupload data e-BKJH tersebut.

\section{d. Metode}

Metodeyangdigunakan pada surveilans kesehatan haji di Dinas Kesehatan KotaSurabayaberdasarkanpedoman penyelenggaraan kesehatan haji dari Kementerian Kesehatan.Metode tersebut berupa melakukan pemeriksaan kesehatan awal dan pemeriksaan lajutan pada jamaah haji.

\section{e. Data}

Data pada surveilans kesehatan haji Dinas Kesehatan Kota Surabaya dikumpulkan berdasarkan sistem pencatatan dan pelaporanselama musim haji dari Puskesmas melalui pemeriksaan kesehatan awal dan pemeriksaan kesehatan kedua. Data Jamaah Haji yang bersumber dari departemen Agama yang diperoleh dari SISKOHATKES, ada beberapa jamaah yang bukan dari Surabaya atau alamat yang salah. Data jamaah juga selalu berubah dan perubahan yang terjadi oleh kementerian agama tidak segera dilaporkan ke dinas kesehatan.

Data kesakitan diperoleh dari data primer hasil pemeriksaan kesehatan yang dilakukan oleh Puskesmas, jamaah masih ada yang belum mau melakukan 
pemeriksaan kesehatan jika tidak mendekati waktu keberangkatan. Data faktor risiko seperti merokok, kurang aktifitas, pakai alat bantu, dan usia $\geq 60$ tahun di peroleh dari data primer hasil pemeriksaan kesehatan. Hasil dari pemeriksaan tersebut diperoleh data bahwa masih banyakjamaah masih belum memahami akan pentingnya dilakukan pemeriksaan tersebut.

Data vaksinasi diperoleh dari data primer yang dikumpulkan oleh puskesmas, hingga saat ini vaksin MM masih belum tersedia di puskesmas. Seharusnya pelaksanaan pemberian vaksinasi 3 bulan sebelum keberangkatan haji tepatnya 20 Mei 2014 tetapi vaksin masih belum datang. Data pemantauan setelah pulang haji diperoleh dari data primer yang dilakukan oleh puskesmas, tetapi data tidak terkumpul dengan optimal karena tersedia form pengumpulan data masih secara manual belum masuk dalam sistem pelaporan secara online melalui SISKOHATKES

\section{Gambaran Proses}

Proses merupakan elemen dari sistem yang bertugas untuk mengolah atau memproses seluruh data menjadi informasi yang lebih berguna.

\section{a. Pengumpulan data}

Proses pengumpulan data surveilans kesehatan haji di Dinas Kesehatan KotaSurabayadimulai dari diperolehnya data jamaah haji dari departemen agama kemudian data tersebut disebar luaskan ke Puskesmas. Pengumpulan data selanjutnya berupa data hasil pemeriksaan pertama dan keduajamaah haji yang dilakukan oleh Puskesmas yaitu 3 bulan sebelum pelaksanaan ibadah haji pada bulan Mei.

Pengumpulan data surveilans kesehatan haji dilakukan oleh petugas puskesmas dengan melakukanrekapitulasi data status kesehatan jamaah yangsesuai dengan form e-BKJH dan atau Siskohatkes, pengumpulan data tersebut dilakukan setiap tahun selama musim haji berlangsung. Data dikumpulkan dari jamaah haji yang telah mendaftarkan diri dengan melakukan pemeriksaan pertama masih ada kendala dalam mengirim data hasil pemeriksaan melalui SISKOHATKES akibat internet yang lambat. Selain itu akibat dari kemampuan pengumpul data atau petugas puskesmas masih kurang lancar dalam proses memasukkan data hasil pemeriksaan

\section{b. Kompilasi data}

Data yang telah terkumpul secara otomatis akan dikelompokkan dalam sistem Siskohatkes. Semua jenis data tersebut dilakukan pengelompokan setiap hari, untuk keperluan pengisian laporan harian, yang nantinya akan dijadikan satu dalam bentuk laporan akhir pelaksanaan surveilans kesehatan haji.

\section{c. Analisis dan interpretasi data}

Data surveilans kesehatan jamaah yang ada langsung diolah dan dianalisis secara langsung dalam sistem Siskohatkes untuk menghasilkan informasi.Analisis data baru berdasarkan tempat, waktu, dan orang.Penyajian data membuat grafik jumlah distribusi jamaah haji risiko tinggi menurut jenis kelamin dan jenis risiko tingginya.Interpretasi data hasil analisis dilakukan dengan cara melihat kecenderungan atau trend jamaah risiko tinggi berdasarkan waktu (membandingkan dengan tahun sebelumnya) dan jenis kelamin.

\section{d. Pencatatan dan Pelaporan}

Pelaksanaan pencatatan dan pelaporan terdapat 62 Puskesmas yang melaksanakan entry data. Data diperoleh dari hasil pemeriksaan kesehatan awal 
dan pemeriksaan kesehatan lanjutan, kemudian di upload melalui applikasi puskesmas (siskohat bidang kesehatan)hasil entry data tersebut didesiminasikan ke Dinas Kesehatan Kota Surabaya.

Dinas kesehatan Kota Surabaya melaksanakan pencatatan dan pelaporan hasil kegiatan pengumpulan data yang dilakukan oleh puskesmasmelalui applikasi SISKOHATES (Siskohat Bidang Kesehatan) dan dikirim (uploads) ke www.siskohatkes.net dengan koneksi internet. Jadwal laporan Dinas Kesehatan KotaSurabaya ke Dinas Kesehatan Provinsi dan web paling lambat tiga minggu sebelum operasional haji dimulai.

\section{Gambaran Output}

Output merupakan hasil dari masukan yang telah diproses oleh bagian pengolahan dan merupakan tujuan akhir dari suatu sistem.

\section{a. Informasi}

Informasi yang dihasilkan oleh surveilans kesehatan haji di Dinas Kesehatan KotaSurabaya yaitu jumlah jamaah haji Kota Surabaya berdasarkan jenis kelamin dan golongan umur, hasil pemeriksaan kesehatan jamaah, hasil pelaksanaan vaksinasi yang telah dilakukan, distribusi penyakit padajamaah haji, danhasil pemeriksaan kehamilan jamaah berupa status kesehatan masing-masing jamaah haji apakah jamaah berisiko atau tidak dan juga obat - obatan yang perlu dibawa oleh jamaah haji. Informasi yang diperoleh berupa seluruh jamaah haji yang berangkat sudah terekam $100 \%$, hal ini sudah sesuai dengan cakupan yang seharusnya bahwa cakupan seluruh jamaah yang berangkat harus terekam $100 \%$. Informasi jumlah jamaah yang diperiksa 3 bulan sebelum berangkat masih mencapai 73\%, serta cakupan pelaporan jamaah haji pulang masih rendah.

\section{b. Indikator kinerja}

Indikator kinerja surveilans kesehatan haji di Dinas Kesehatan KotaSurabayaadalah kelengkapan laporan sebesar 100\%, dan ketepatan laporan sebesar $100 \%$.Indikator output dalam pemantauan surveilans kesehatan haji yang dilakukan oleh Dinas Kesehatan Kota Surabaya adalah :

1) Cakupan seluruh jamaah haji yang berangkat harus terekam

2) Cakupan jumlah jamaah haji yang diperiksa sebelum 3 bulan keberangkatan

3) Cakupan pemeriksaan jamaah pulang haji dilakukan selama 14 hari

\section{c. Diseminasi informasi}

Dinas kesehatan melakukan analisis data hasil penyelenggaraan kesehatan haji di wilayahnya dan didesiminasikan ke Puskesmas, Dinas Kesehatan Provinsi dan pihak-pihak lain yang terkait misalnya ke Kantor Kesehatan Pelabuhan wilayah Surabaya.Diseminasi informasi disampaikan kepada Dinas Kesehatan Provinsi dan Puskesmas dalam bentuk rapat dengan semua kepala puskesmas pada pertemuan evaluasi pelaksanaan pemeriksaan pertama dan pemeriksaan kedua.

\section{SIMPULAN DAN SARAN Simpulan}

Pelaksanaan surveilans kesehatan haji diperoleh data berupa data jamaah berisiko sebanyak 1428 (67\%), umur 
terbanyak jamaah haji berusia 50-59 tahun 763 (36\%), jamaah haji paling banyak berjenis kelamin wanita 1138 (54\%), pemeriksaan kehamilan dengan hasil negatif sebanyak 640 (56\%), dan kategori jamaah dalam observasi sebanyak 1375 (65\%).

Program yang digunakan untuk mengolah data adalah sistem Komputer Terpadu Kesehatan Haji (SISKOHATKES) yang dilakukan secara online.Informasi epidemiologi berupa informasi cakupan seluruh jamaah yang berangkat harus terekam 100\%, jamaah yang diperiksa 3 bulan sebelum berangkat masih mencapai $73 \%$ seharusnya $80 \%$. Output dari surveilans kesehatan haji berupa diseminasi informasi berupa laporan dan umpan balik ke puskesmas pada akhir musim haji melalui rapat bulanan. Informasi yang dihasilkan dari sistem surveilans kesehatan haji dapat digunakan untuk mencegah penyebaran infeksi dari jamaah haji ke daerah asal jamaah. Beberapa penyakit dari tempat ibadah haji memiliki karakteristik masa inkubasi yang panjang, sehingga dibutuhkan pengawasan atau surveilans pasif dengan menggunakan jaringan seluler yang inovatif. ${ }^{8}$

\section{Saran}

Disarankan meningkatkan pendekatan kepada jamaah haji oleh petugas puskesmas untuk melakukan pembinaan dengan membuat pengembangan suatu media informasi agar calon jamaah haji dapat rutin untuk melakukan pemeriksaan kesehatan.

\section{DAFTAR RUJUKAN}

1] Departemen Kesehatan RI. 2008. Bahan Bacaan Peserta Pelatihan Petugas Pemeriksa Kesehatan
Jamaah Calon Haji (Tahap I \& II). Jakarta

2] Ariyanto. 2012. Faktor Risiko Kesehatan Saat Berhaji. (Serial Online). http://www.kespelsemarang.com/ kkp/bacaberita.php?milihndi=75. (Akses tanggal 10 Juni 2015)

3] Departemen Kesehatan RI.2010. Pedoman Teknis Pemeriksaan Kesehatan Jamaah Haji.Jakarta

4] Kementerian Kesehatan RI. 2012. Profil Kesehatan Haji Indonesia Tahun 2012. Jakarta

5] Departemen Kesehatan RI.2009.Pedoman

Penyelenggaraan Kesehatan Haji. Jakarta

6] Departemen Kesehatan RI .2003. Keputusan Menteri Kesehatan RI No.1479/MENKES/SK/X/2003 tentang Sistem Surveilans Epidemiologi Kesehatan

7] Timmreck.2004. Epidemiologi Suatu Pengantar.Jakarta : EGC

8] Karami.2013.Public Health Surveillance and Hajj Pilgrimate as a Mass Gathering. Iranian J Publ Health. Vol.42, No.7,PP.791-792

9] Pane, M.,Imari, S.,Alwi,Q.,Nyoman Kandun,I.,Cook, A.R.,\& Samaan,G.,2013. Causes of Mortality for Indonesian Hajj Pilgrims : comparison between routine Death certificate adverbal autopsy findings.ploS one.Vol.8, No.8

10] Handajani,A.,Roossihermiatie, B., \& Maryani H., 2010. Faktor-faktor yang berhubungan dengan pola kematian pada penyakit degeneratif di Indonesia. Buletin Penelitian Sistem Kesehatan. Vol.13, No.1, p 42-53

11] Razavi, S.M., Sabouri-Kashani, A., \& Ziaee-ardakani,H.,2013. Trend of Diseases Among Iranian Pilgrims 
116 Jurnal IKESMA Volume 13 Nomor 2 September 2017

During Five Consecutive Years

Based on a Syndromic Survellance System in Hajj.MJRI, Vol.27, No.4, p 179-185

12] Shimemeri, A.2012. Cardivascular Disease In Hajj Pilgrims. Journal of Saudi Heart Association. Vol.24, No.2, p123-7 